Corrigendum

\title{
Corrigendum to "Reduced Oxidative Stress Contributes to the Lipid Lowering Effects of Isoquercitrin in Free Fatty Acids Induced Hepatocytes"
}

\author{
Waseem Hassan, Gao Rongyin, Abdelkader Daoud, Lin Ding, \\ Lulu Wang, Jun Liu, and Jing Shang \\ National Center for Drug Screening and State Key Laboratory of Natural Medicines, China Pharmaceutical University, \\ No. 24 Tongjiaxiang, Nanjing, Jiangsu 210009, China \\ Correspondence should be addressed to Jing Shang; shangjing21cn@163.com \\ Received 9 December 2014; Accepted 16 December 2014 \\ Copyright (C) 2015 Waseem Hassan et al. This is an open access article distributed under the Creative Commons Attribution License, \\ which permits unrestricted use, distribution, and reproduction in any medium, provided the original work is properly cited.
}

The pictures for "FFA $(1 \mathrm{mM})+$ simva." treatment groups (in Figures 4(a), 4(c), 6(a), and 6(b)) and "FFA (1 mM) + IQ $(5 \mu \mathrm{M})$ (in Figure $4(\mathrm{c}))$ " were misrepresented inadvertently. Corrected figures are given here.

The western blot for AMPK in Figure 10(a) is provided in a correct sequence of treatment. 
Control

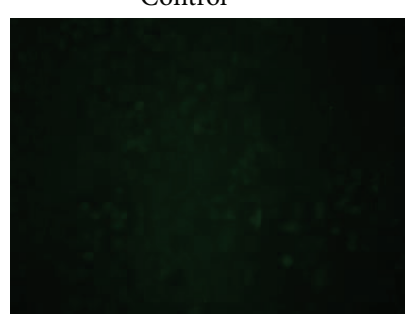

FFA $(1 \mathrm{mM})+\mathrm{IQ}(5 \mu \mathrm{M})$

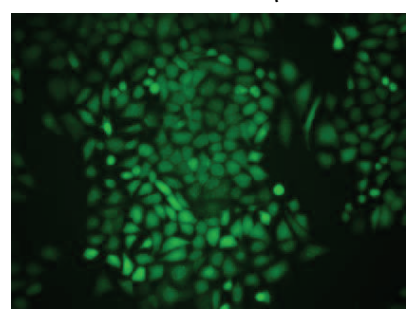

FFA $(1 \mathrm{mM})+$ IQ $(30 \mu \mathrm{M})$

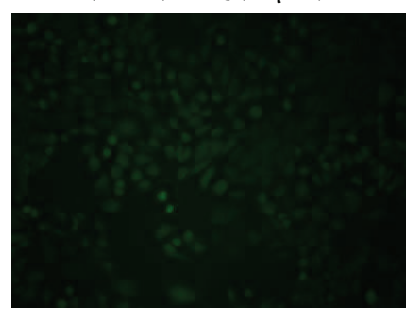

FFA ( $1 \mathrm{mM})$

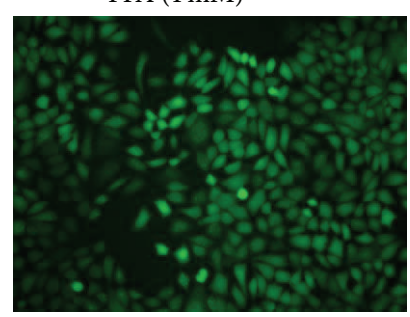

FFA $(1 \mathrm{mM})+$ IQ $(10 \mu \mathrm{M})$

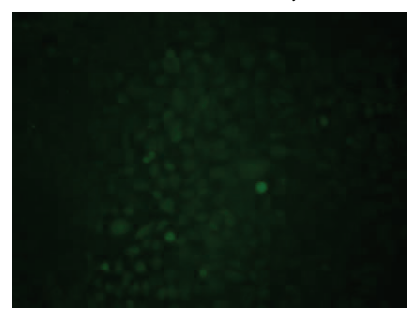

FFA $(1 \mathrm{mM})+\mathrm{IQ}(50 \mu \mathrm{M})$

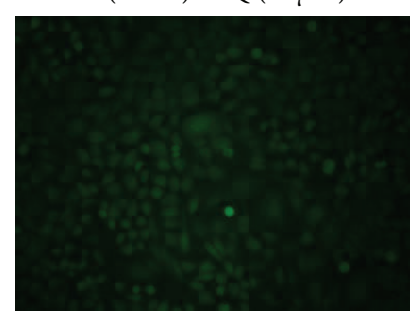

(a)

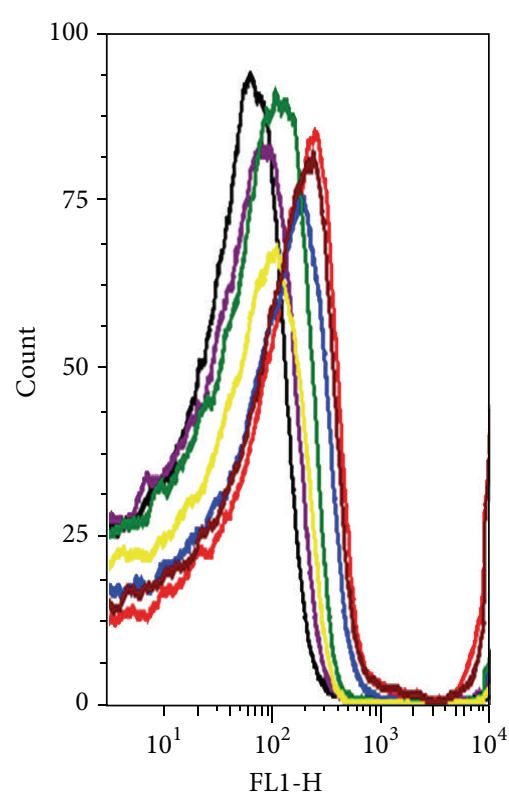

FL1-H

- Control

- FFA $(1 \mu \mathrm{M})$

- FFA $(1 \mu \mathrm{M})+\mathrm{IQ}(5 \mu \mathrm{m})$

- FFA $(1 \mu \mathrm{M})+\mathrm{IQ}(10 \mu \mathrm{m})$

- FFA $(1 \mu \mathrm{M})+\mathrm{IQ}(30 \mu \mathrm{m})$

FFA $(1 \mu \mathrm{M})+\mathrm{IQ}(50 \mu \mathrm{m})$

_ FFA $(1 \mu \mathrm{M})+$ Simva. $(10 \mu \mathrm{M})$

)
FFA $(1 \mathrm{mM})+$ simva.
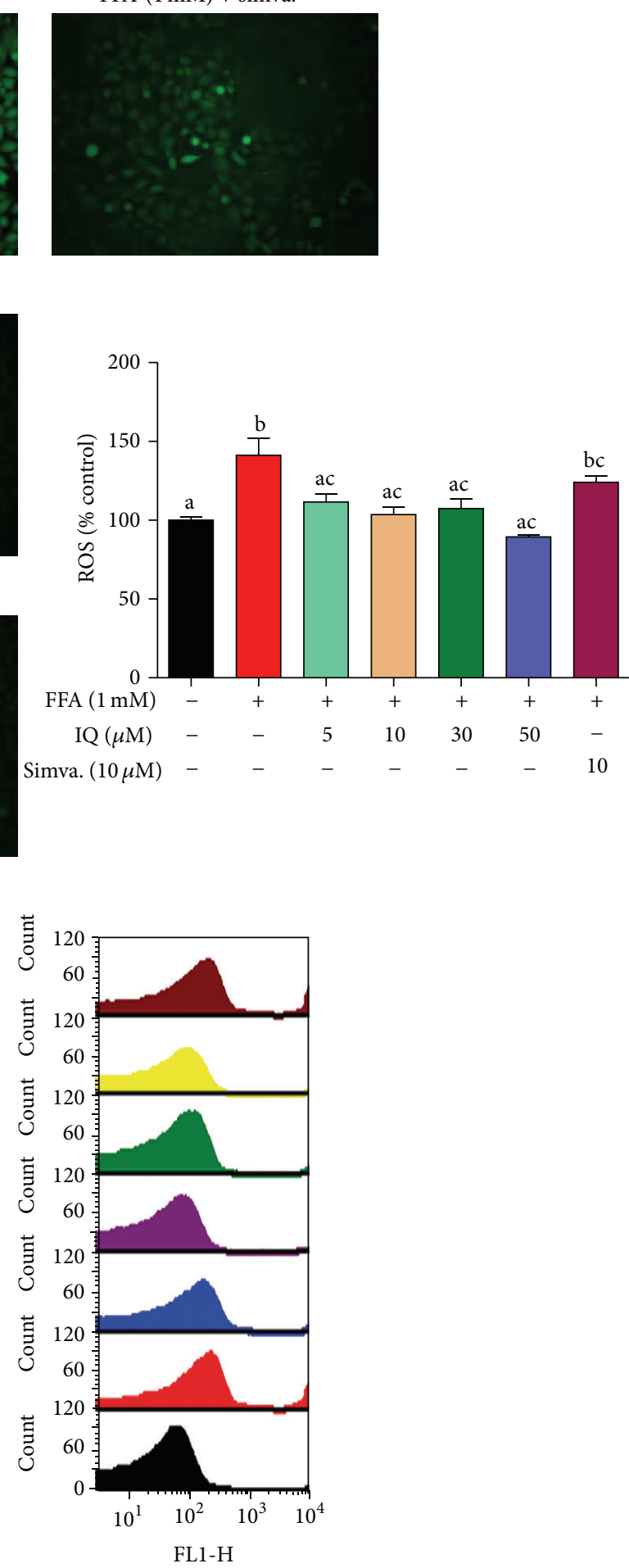

Control

FFA $(1 \mu \mathrm{M})$

- FFA $(1 \mu \mathrm{M})+$ IQ $(5 \mu \mathrm{m})$

FFA $(1 \mu \mathrm{M})+\mathrm{IQ}(10 \mu \mathrm{m})$

FFA $(1 \mu \mathrm{M})+$ IQ $(30 \mu \mathrm{m})$

FFA $(1 \mu \mathrm{M})+\mathrm{IQ}(50 \mu \mathrm{m})$

- FFA $(1 \mu \mathrm{M})+$ Simva. $(10 \mu \mathrm{M})$

(b) 


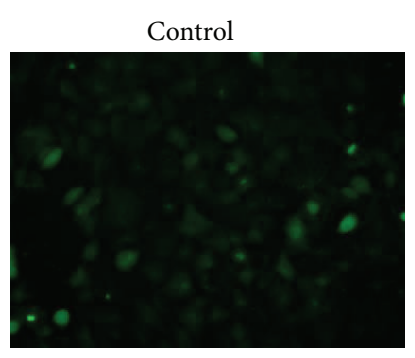

FFA $(1 \mathrm{mM})+\mathrm{IQ}(5 \mu \mathrm{M})$

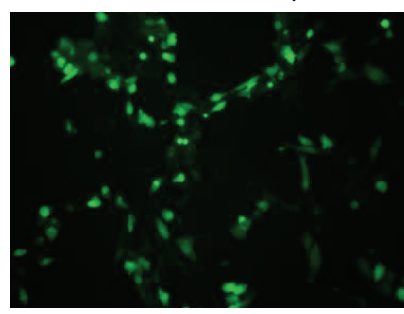

FFA $(1 \mathrm{mM})+$ IQ $(30 \mu \mathrm{M})$

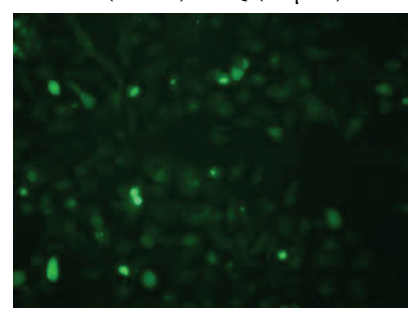

FIGURE 4: Effects of IQ on ROS in FFA induced primary rat hepatocytes and BRL-3A cells. (a) shows the pictographs of effects of IQ on BRL-3A cells. Magnification $\times 200$. (b) illustrates the histograms from flow cytometry showing effects of IQ on primary rat hepatocytes. (c) demonstrates the pictographs of primary rat hepatocytes exhibiting effects of IQ. Magnification $\times 200$. The data represents \pm SD. $P<0.05$ was considered as statistically significant. Different superscripts letters demonstrate the significant statistical difference as calculated by ANOVA followed by Tukey's test.
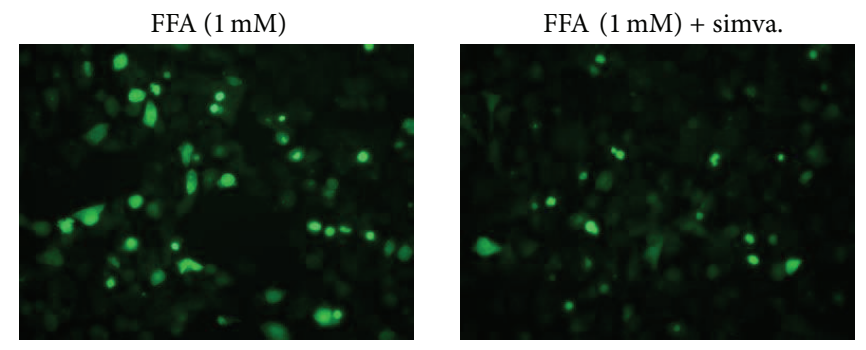

FFA $(1 \mathrm{mM})+\mathrm{IQ}(10 \mu \mathrm{M})$

FFA $(1 \mathrm{mM})+$ IQ $(50 \mu \mathrm{M})$

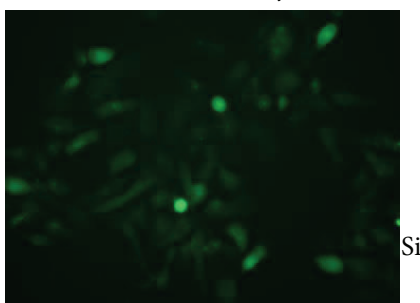

(c)

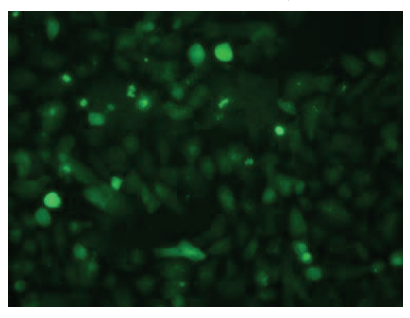

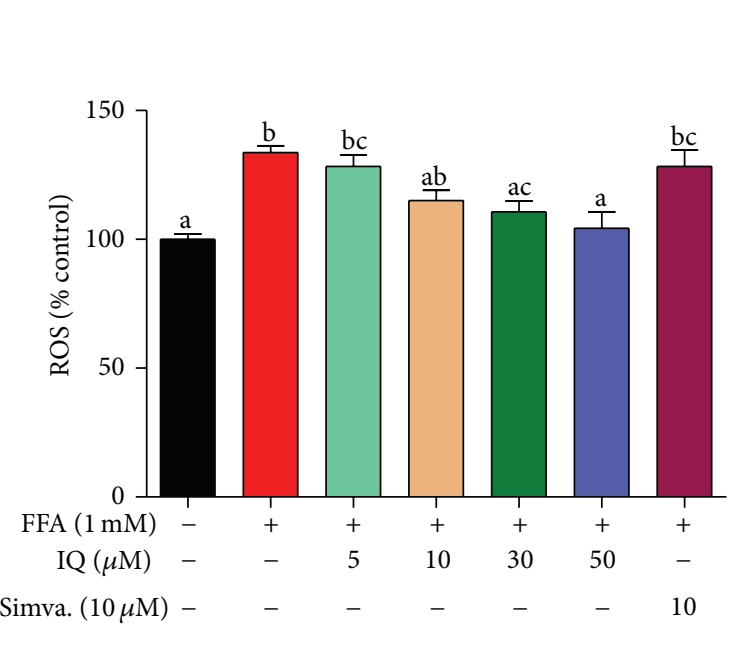

o 

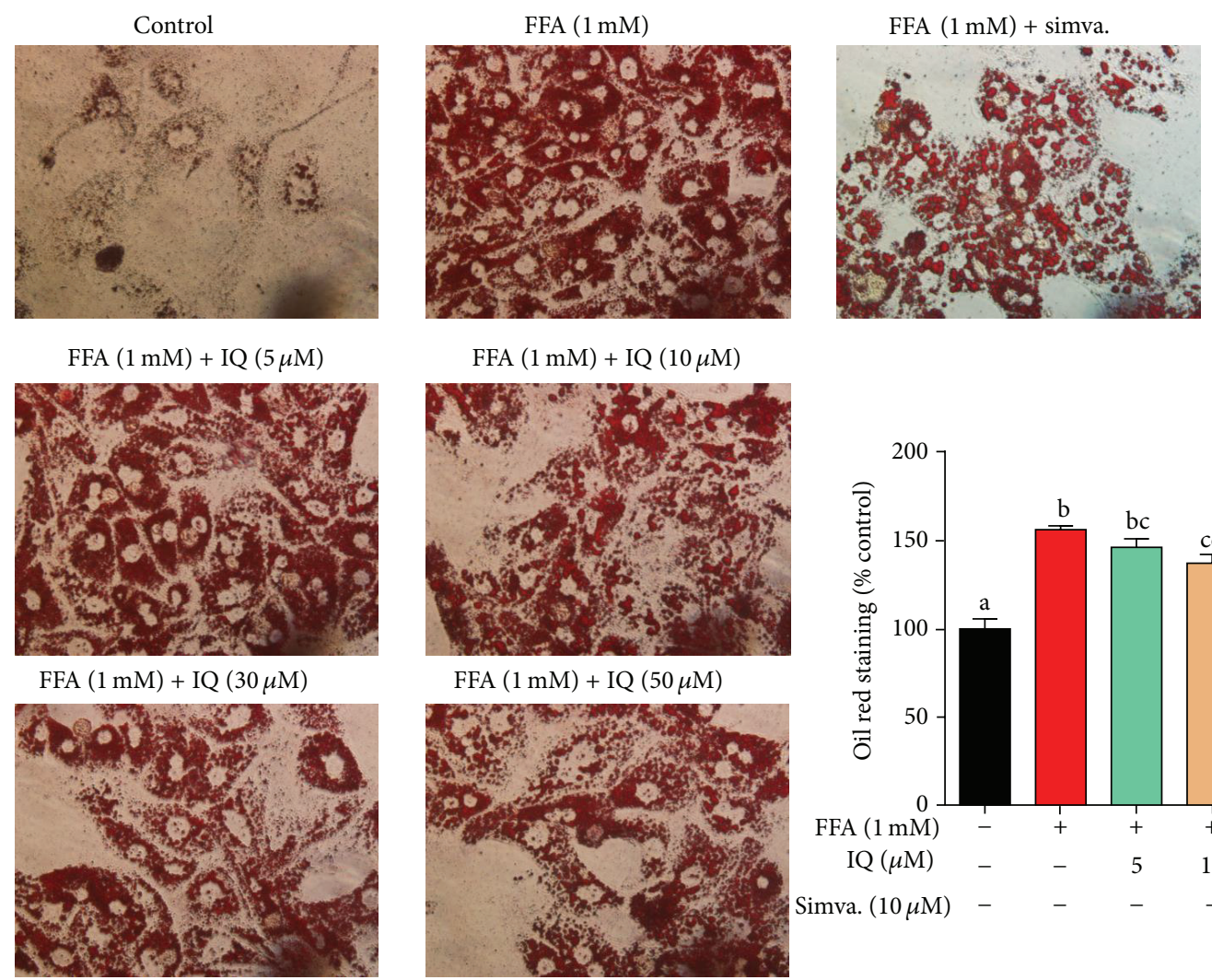

FFA $(1 \mathrm{mM})+\mathrm{IQ}(50 \mu \mathrm{M})$
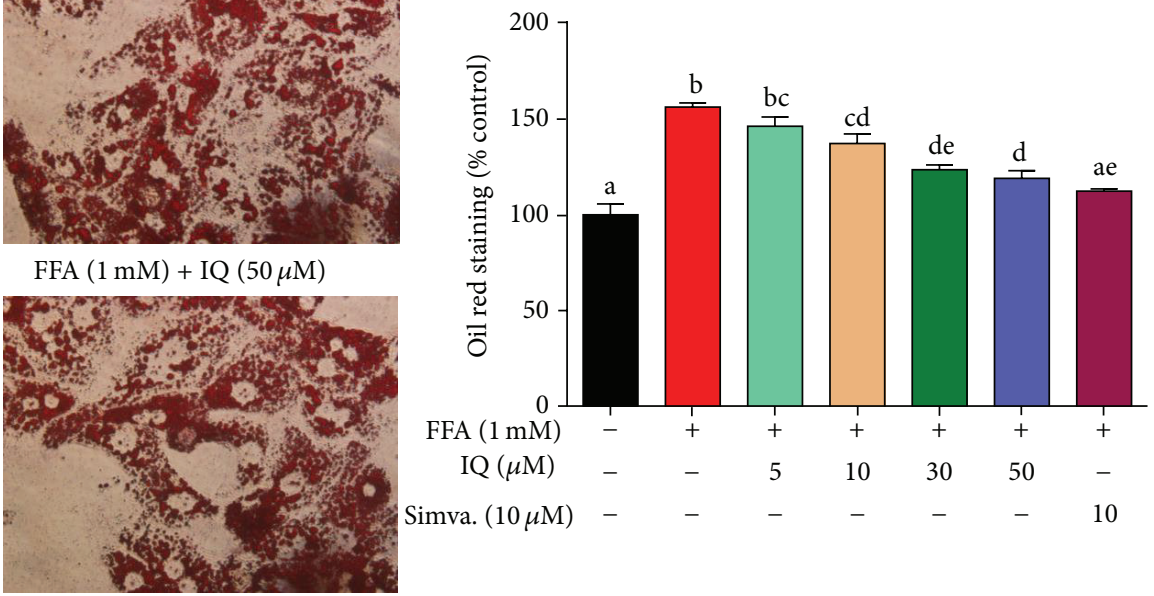

(a)
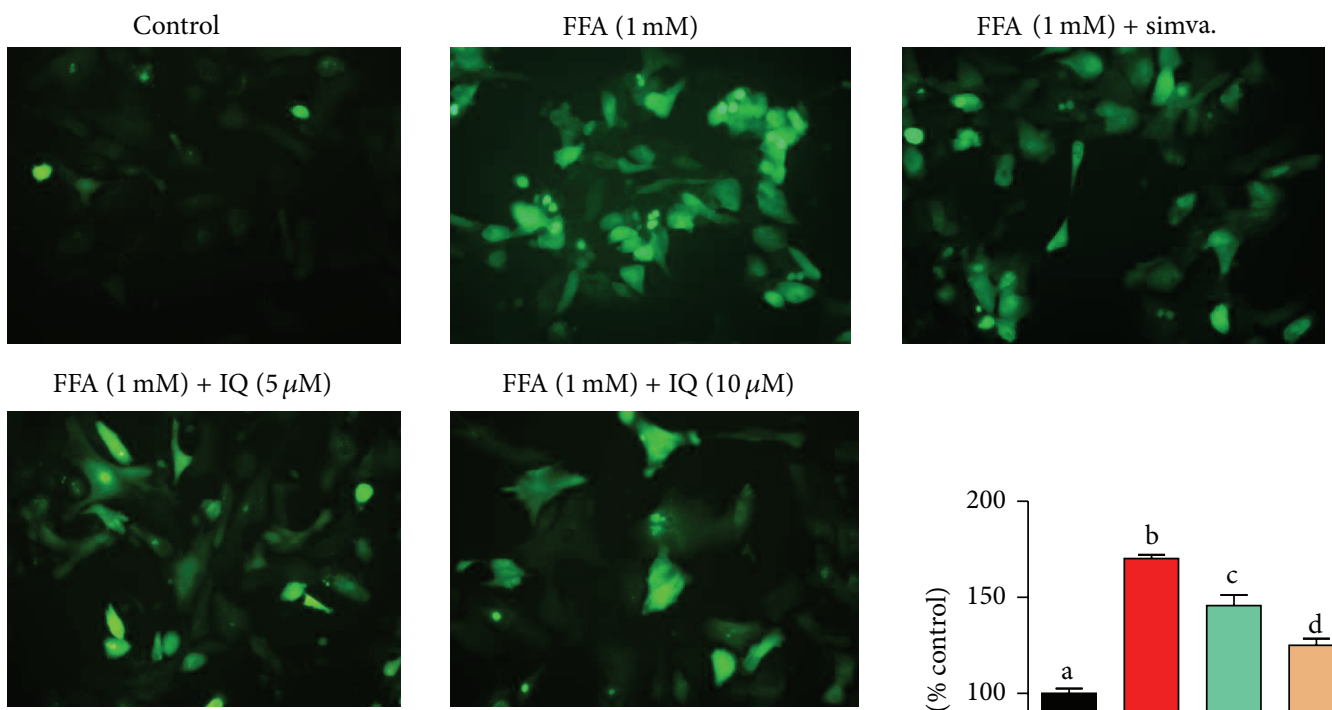

FFA $(1 \mathrm{mM})+\mathrm{IQ}(10 \mu \mathrm{M})$

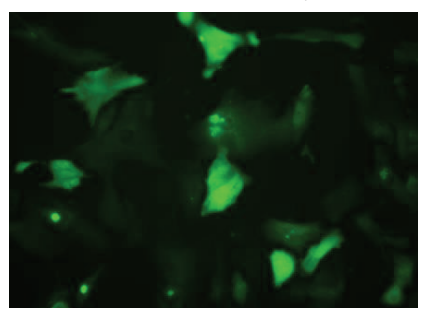

FFA $(1 \mathrm{mM})+\mathrm{IQ}(30 \mu \mathrm{M})$

FFA $(1 \mathrm{mM})+\mathrm{IQ}(50 \mu \mathrm{M})$
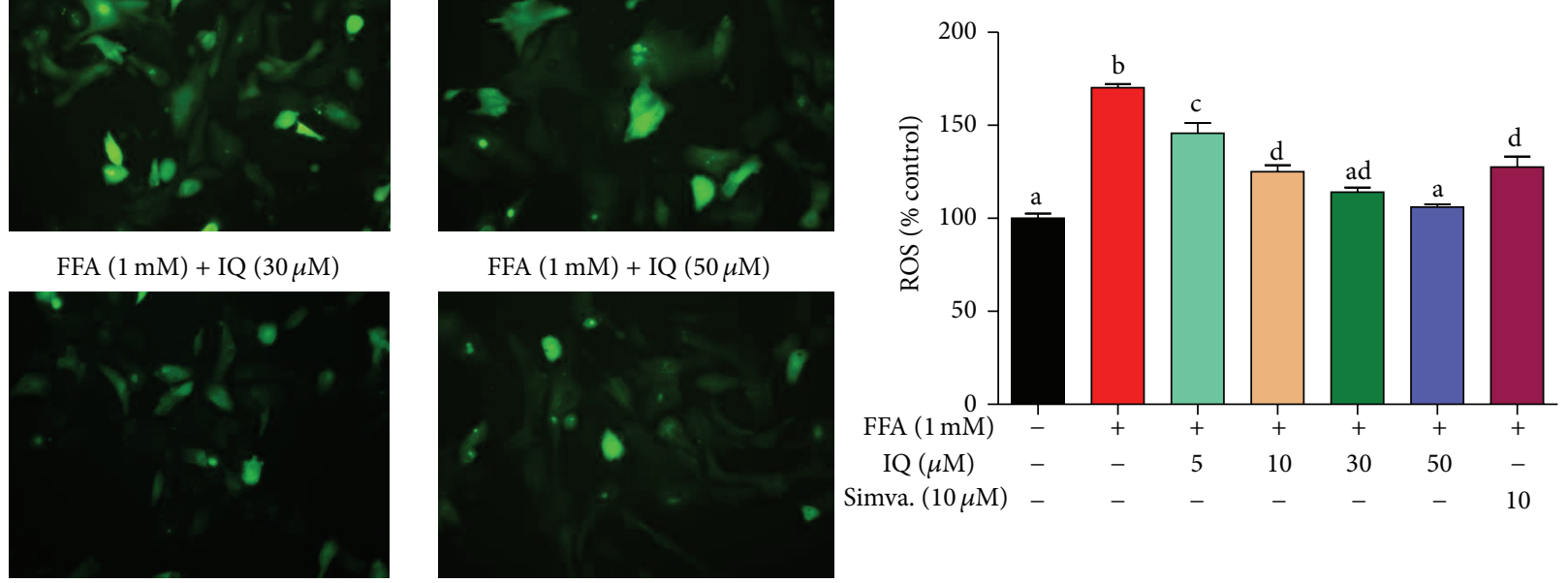

(b)

FIGURE 6: Effects of IQ on intracellular lipid accumulation and ROS levels. Primary rat hepatocytes were treated with FFA for 24 hours first and then treated with IQ for another 24 hours. Lipid accumulation was determined by oil red staining while ROS was analyzed with H2DCFDA by the method described in Methods. (a) shows the effects of IQ on lipid accumulation; (b) displays the effects of IQ on ROS. The data represents \pm SD. $P<0.05$ was considered as statistically significant. Different superscripts letters demonstrate the significant statistical difference as calculated by ANOVA followed by Tukey's test. 

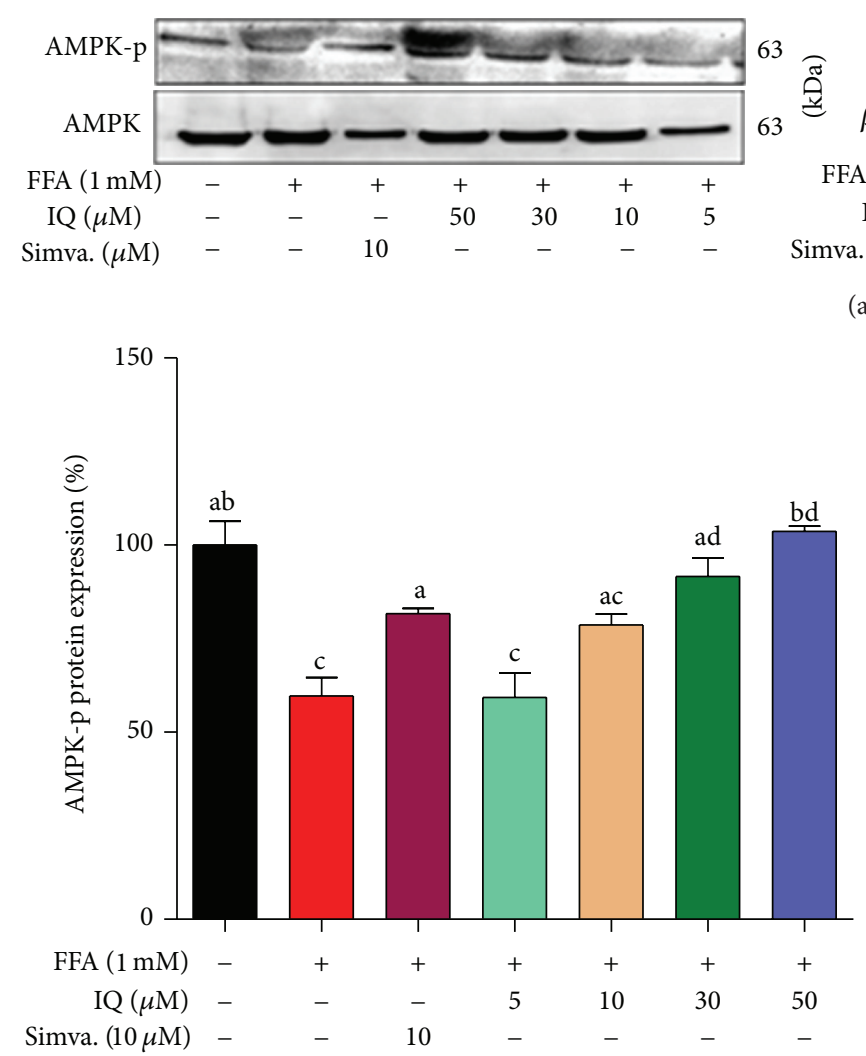

(b)

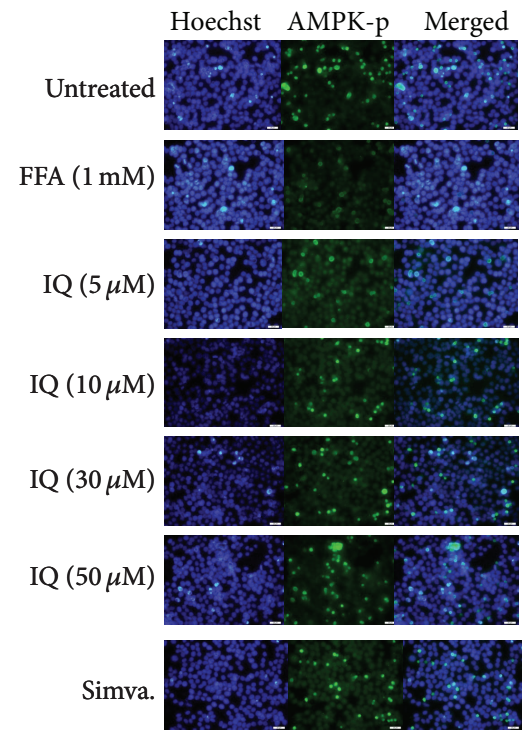

(d)

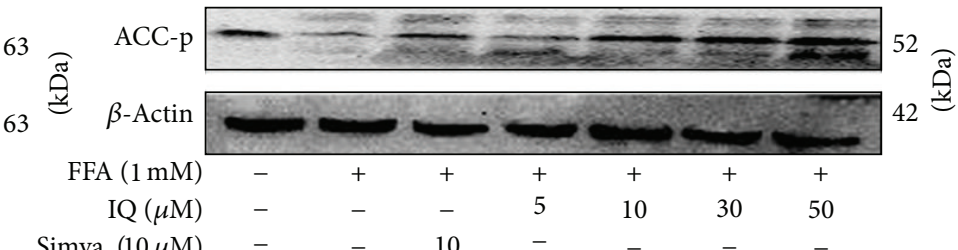

(a)

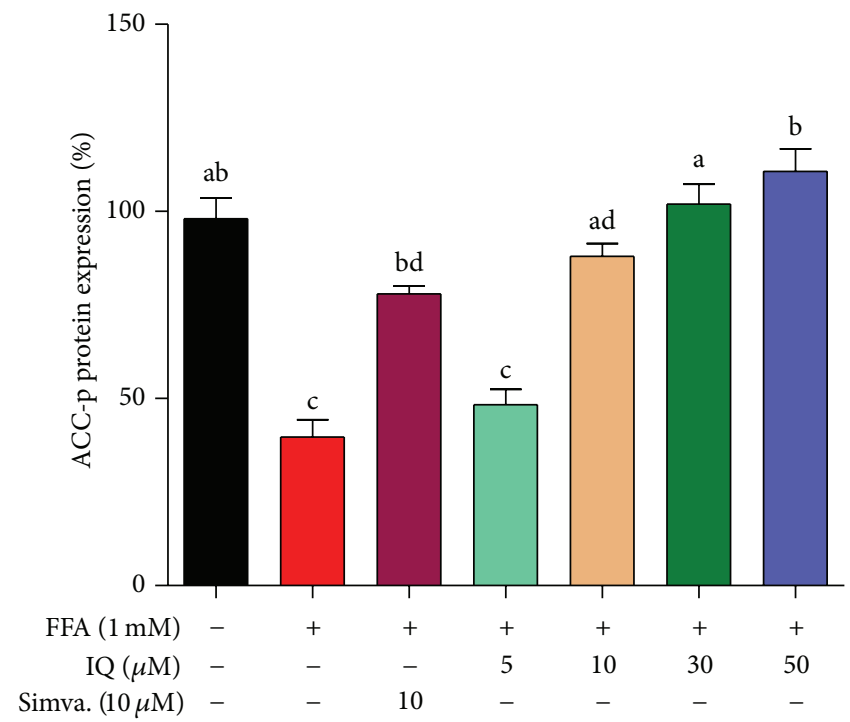

(c)

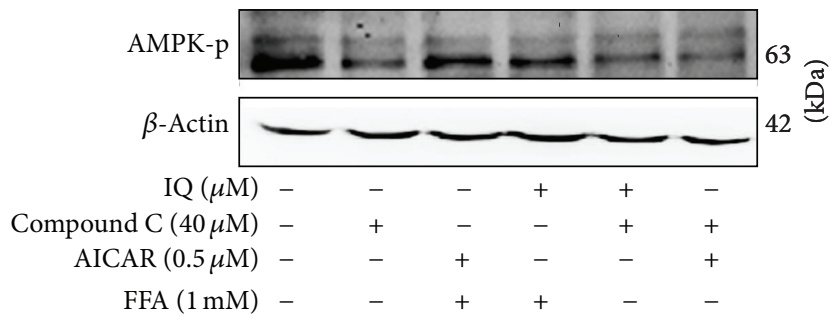

(e)

FIGURE 10: Validation for the effects of IQ in regulating AMPK pathway. (a) Representative western blots of AMPK, AMPK-p (and (b)), and ACC-p (and (c)). Primary rat hepatocytes were treated with FFA to induce the cells and coadministered with IQ or simvastatin for 24 hours to observe the changes in protein expression. (d) illustrates the immunofluorescence pictographs for p-AMPK expression in FFA induced primary rat hepatocytes. (e) shows the actions of IQ and AICAR on compound C blocked primary rat hepatocytes. Cells were treated with compounds C, IQ, and AICAR alone with or without the presence of FFA. Alternatively, IQ and AICAR were coadministered with compound $\mathrm{C}$ to draw comparisons. The data represents \pm SD. $P<0.05$ was considered as statistically significant. Different superscripts letters demonstrate the significant statistical difference as calculated by ANOVA followed by Tukey's test. 


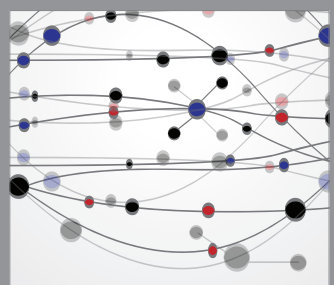

The Scientific World Journal
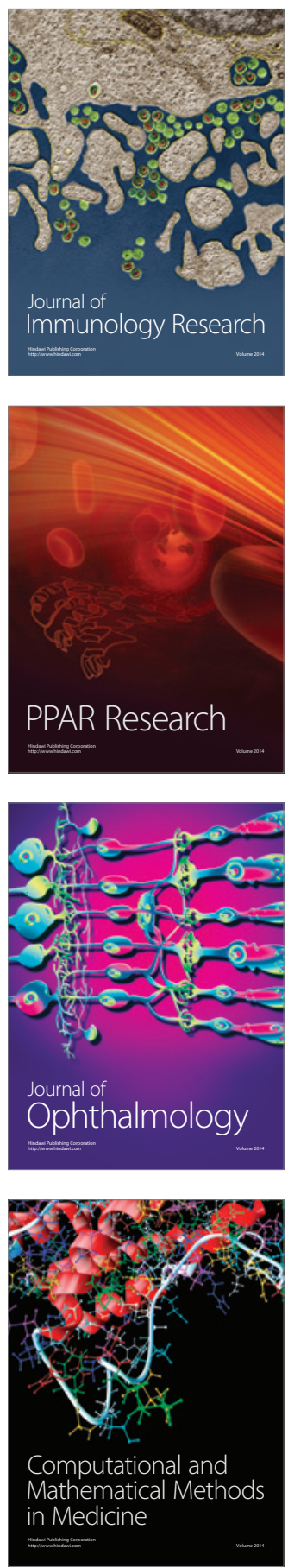

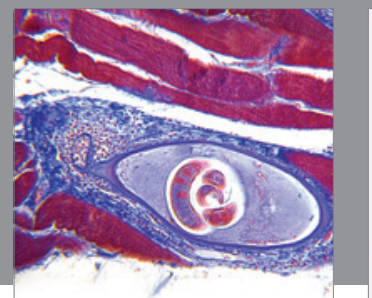

Gastroenterology

Research and Practice
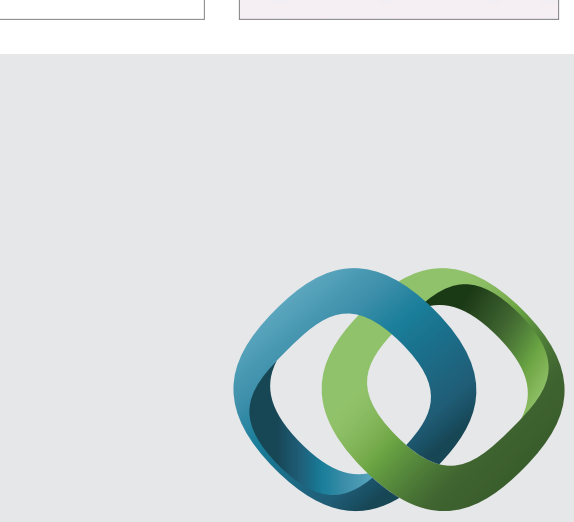

\section{Hindawi}

Submit your manuscripts at

http://www.hindawi.com
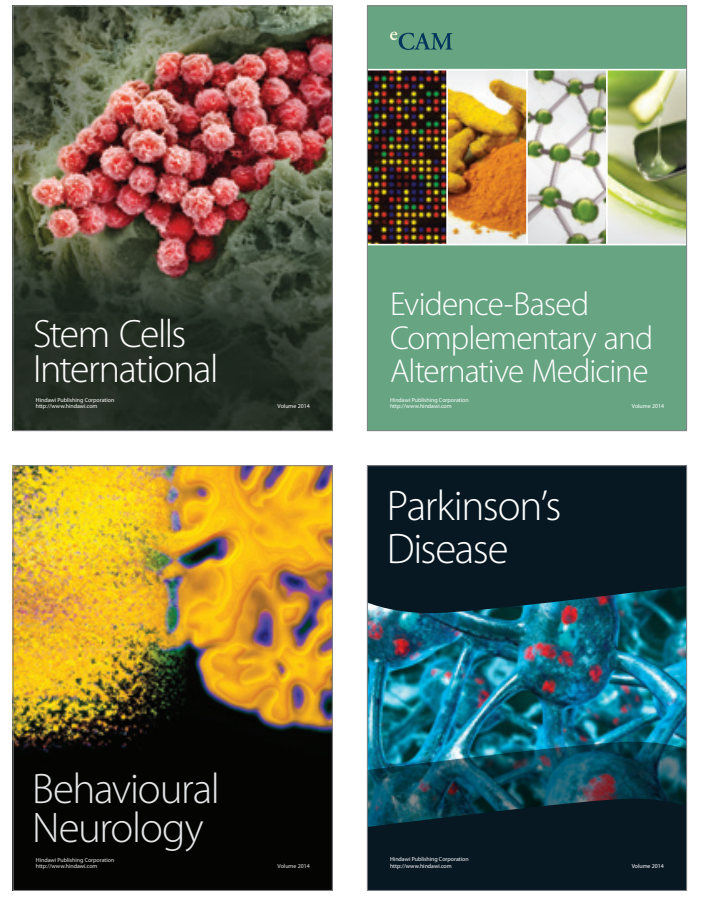
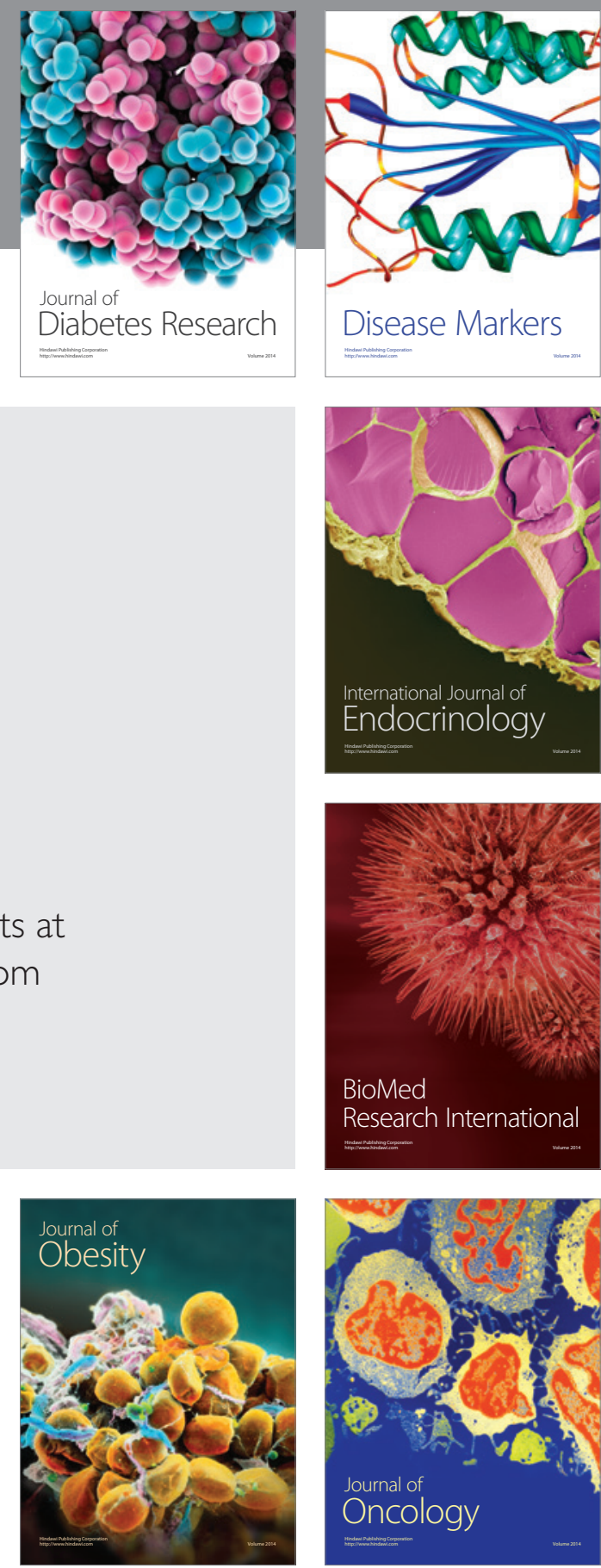

Disease Markers
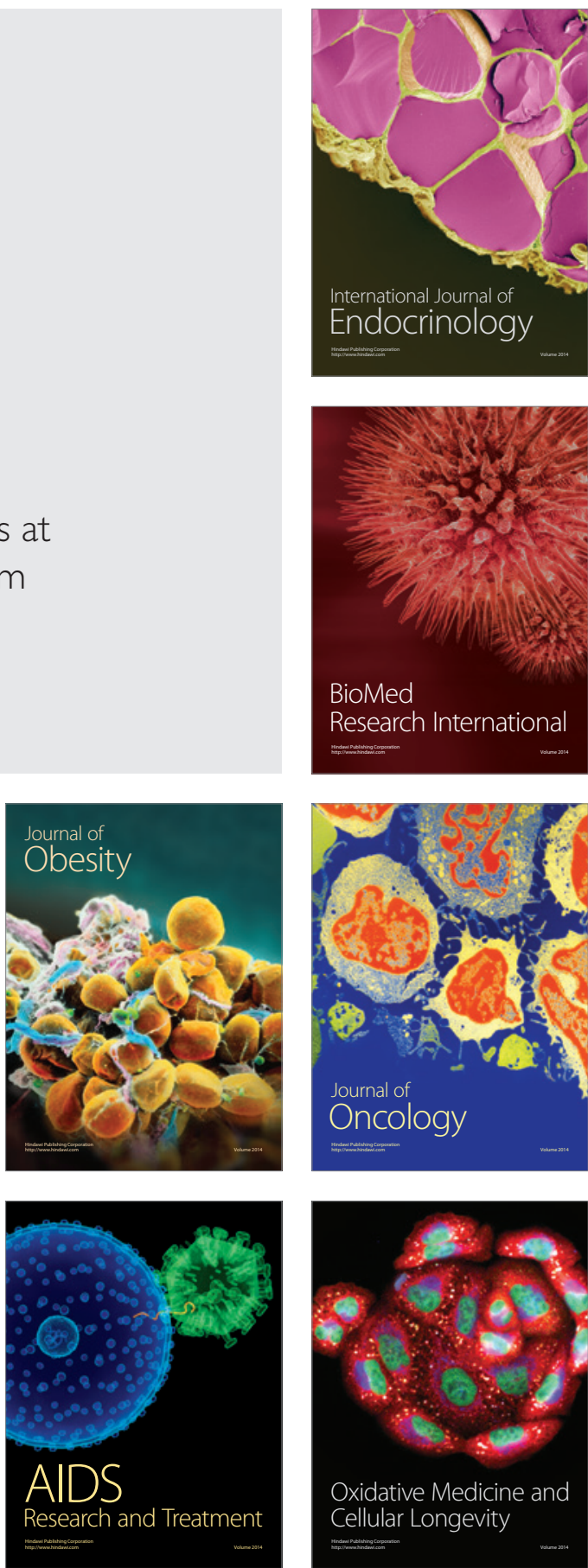